\title{
CTX-M-15-producing Enteroaggregative Escherichia coli as Cause of Travelers' Diarrhea
}

\section{Elisabet Guiral, Eva Mendez-Arancibia, Sara M. Soto, Pilar Salvador, Anna Fàbrega, Joaquim Gascón, and Jordi Vila}

Travelers' diarrhea is a major public health problem. From patients in whom diarrhea developed after travel to India, 5 enteroaggregative Escherichia coli strains carrying $\beta$-lactamase CTX-M-15 were identified; 3 belonged to clonal complex sequence type 38 . This $\beta$-lactamase contributes to the multidrug resistance of enteroaggregative $E$. coli, thereby limiting therapeutic alternatives.

$\mathrm{T}$ ravelers' diarrhea remains a major public health problem, causing substantial illness and disability. Almost 50\% of patients with travelers' diarrhea require treatment with antimicrobial drugs because of persistence or severity of signs and symptoms (1). Enteroaggregative E. coli (EAEC) is among the most common diarrheagenic E. coli pathotypes recognized (2). The first-choice agents for treating EAEC infections are quinolones, rifaximin, azithromycin, and cephalosporins. However, the number of pathogenic $E$. coli strains resistant to multiple antimicrobial agents has increased, and resistance to third-generation cephalosporins (e.g., ceftazidime, ceftriaxone, or cefotaxime) associated with production of extended-spectrum $\beta$-lactamases (ESBLs) limits therapeutic options (3).

Although ESBL production has mainly been shown in extraintestinal $E$. coli infections, studies concerning effects of ESBLs in intestinal E. coli infections are scarce. The worldwide spread of CTX-M-15 type ESBLs has led these $\beta$-lactamases to replace TEM- and SHV-type ESBLs in Europe, Canada, and Asia and become one of the major groups of ESBLs studied. Of the different CTX-M-type ESBLs, CTX-M-15 has become the most widely distributed enzyme worldwide. It was first identified in an isolate from India in 1999 and thereafter became prevalent around

Author affiliations: August Pi i Sunyer Biomedical Research Institute, Barcelona, Spain (E. Guiral, E. Mendez-Arancibia, S.M. Soto, P. Salvador, A. Fàbrega, J. Vila); Barcelona Centre for International Health Research, Barcelona (J. Gascón); and University of Barcelona, Barcelona (J. Vila)

DOI: http://dx.doi.org/10.3201/eid1710.110022 the world (4). CTX-M-15 enhances hydrolytic activity against ceftazidime (5). A particular clone of CTX-M-15producing E. coli, characterized by phylogenetic type (phylotype) B2 and sequence type 131 (ST131), seems to be largely responsible for international epidemics of CTX-M-producing E. coli (6). Sequence types (STs) are grouped into clonal complexes by their similarity to a central allelic profile.

ST131 is a singleton and therefore does not belong to a clonal complex (7). Molecular epidemiologic studies have suggested that the sudden increase in CTX-M-15producing $E$. coli worldwide was mainly caused by this single clone (ST131) and that foreign travel to high-risk areas, such as the Indian subcontinent, might play a partial role in the spread of this clone across continents (8). The $b l a_{\text {CTX-M-15 }}$ gene is usually found downstream from the insertion sequence ISEcp1, which may be involved in the clone's dissemination and expression (9). We describe molecular epidemiology and plasmid analyses of 5 CTX-M-15-producing EAEC isolates from patients with travelers' diarrhea who had traveled from Spain to India.

\section{The Study}

The study included all patients with diarrhea who visited the Tropical Medicine Unit of Hospital Clinic in Barcelona, Spain, during 2005 and 2006. Patients with diarrhea that started during or shortly after ( $<5$ days) a stay in a developing country were eligible. After the participants provided informed consent, clinical and epidemiologic data were collected.

Among all eligible participants, infection with EAEC and no other enteropathogen was found for 51 . Of these 51 EAEC isolates, 5 from patients who had traveled to India were resistant to third-generation cephalosporins. Resistance phenotypes indicated ESBL production. MICs for antimicrobial agents and susceptibility class were determined by using the Clinical and Laboratory Standards Institute breakpoints guideline (Table 1). All strains were resistant to penicillins; second-, third-, and fourth-generation cephalosporins; and all $\beta$-lactamaseinhibitor combinations except piperacillin/tazobactam. Apart from $\beta$-lactam susceptibility, the strains showed resistance to other classes of antimicrobial agents, such as fluoroquinolones, tetracyclines, and monobactams (aztreonam). Positive amplification with specific primers and sequencing for the $b l a_{\mathrm{CTX}-\mathrm{M}-15}$ gene provided positive genotypic confirmatory test results for ESBL production.

The epidemiologic relationships among the 5 strains were studied by repetitive sequence-based PCR, pulsedfield gel electrophoresis, and multilocus sequence typing $(10,11)$. The PCR and pulsed-field gel electrophoresis genomic fingerprinting showed that the 5 strains were not epidemiologically related (Figure 1). However, multilocus 
CTX-M-15-producing Enteroaggregative E. coli

Table 1. Susceptibility of 5 enteroaggregative Escherichia.coli strains that produced diarrhea in patients returning from India, 2005$2006^{*}$

\begin{tabular}{|c|c|c|c|c|c|c|c|c|c|c|c|c|c|c|c|c|c|c|c|c|c|c|c|c|}
\hline \multirow[b]{2}{*}{ Strain } & \multicolumn{24}{|c|}{ Antimicrobial agent } \\
\hline & AM & PR & $A G$ & $\mathrm{P} / \mathrm{T}$ & $\mathrm{A} / \mathrm{S}$ & $\mathrm{FU}$ & FOX & $\mathrm{FZ}$ & PIM & CTX & CAZ & GN & AK & TB & $\mathrm{F}$ & IMI & $\mathrm{ME}$ & $A Z$ & CIP & NOR & LEV & TE & SXT & $\mathrm{CL}$ \\
\hline HC19 & $\mathrm{R}$ & $\mathrm{R}$ & $\mathrm{R}$ & $S$ & $\mathrm{R}$ & $\mathrm{R}$ & I & $\mathrm{R}$ & $\mathrm{R}$ & $\mathrm{R}$ & $\mathrm{R}$ & $\mathrm{R}$ & $S$ & $\mathrm{R}$ & $S$ & $S$ & $S$ & $\mathrm{R}$ & $\mathrm{R}$ & $\mathrm{R}$ & $\mathrm{R}$ & $\mathrm{S}$ & $\mathrm{R}$ & $\mathrm{S}$ \\
\hline HC64 & $\mathrm{R}$ & $\mathrm{R}$ & $\mathrm{R}$ & $S$ & $\mathrm{R}$ & $\mathrm{R}$ & I & $\mathrm{R}$ & $\mathrm{R}$ & $\mathrm{R}$ & $\mathrm{R}$ & $S$ & $S$ & $\mathrm{R}$ & $S$ & S & $S$ & $\mathrm{R}$ & $\mathrm{R}$ & $\mathrm{R}$ & $\mathrm{R}$ & $\mathrm{R}$ & $\mathrm{R}$ & S \\
\hline HC67 & $\mathrm{R}$ & $\mathrm{R}$ & $\mathrm{R}$ & $S$ & $\mathrm{R}$ & $\mathrm{R}$ & I & $\mathrm{R}$ & $\mathrm{R}$ & $\mathrm{R}$ & I & $\mathrm{R}$ & $\mathrm{R}$ & $\mathrm{R}$ & S & $S$ & $S$ & $\mathrm{R}$ & $\mathrm{R}$ & $\mathrm{R}$ & $\mathrm{R}$ & $\mathrm{R}$ & $\mathrm{R}$ & S \\
\hline $\mathrm{HC} 74$ & $\mathrm{R}$ & $\mathrm{R}$ & $\mathrm{R}$ & $S$ & $\mathrm{R}$ & $\mathrm{R}$ & I & $\mathrm{R}$ & $\mathrm{R}$ & $\mathrm{R}$ & $\mathrm{R}$ & $S$ & $\mathrm{R}$ & $\mathrm{R}$ & $S$ & S & $S$ & $\mathrm{R}$ & $\mathrm{R}$ & $\mathrm{R}$ & $\mathrm{R}$ & $\mathrm{R}$ & $\mathrm{R}$ & $\mathrm{R}$ \\
\hline $\mathrm{HC} 6$ & $\mathrm{R}$ & $\mathrm{R}$ & 1 & $S$ & $\mathrm{R}$ & $\mathrm{R}$ & S & $\mathrm{R}$ & I & $\mathrm{R}$ & $S$ & S & S & $S$ & $S$ & $S$ & $S$ & I & $\mathrm{R}$ & $\mathrm{R}$ & $\mathrm{R}$ & $\mathrm{R}$ & $\mathrm{R}$ & $S$ \\
\hline
\end{tabular}

*AM, ampicillin; PR, piperacillin; AG, amoxiclavulanic acid/augmentin; P/T, piperacillin/tazobactam; A/S, ampicillin/sulbactam; FU, cefuroxime; FOX, cefoxitin; FZ, cefazoline; PIM, cefepime; CTX, cefotaxime; CAZ, ceftazidime; GN, gentamicin; AK, amikacin; TB, tobramycin; F, fosfomycin; IMI, imipenem; ME, meropenem; AZ, aztreonam; CIP, ciprofloxacin; NOR, norfloxacin; LEV, levofloxacin; TE, tetracycline; SXT, cotrimoxazole; CL, chloramphenicol; R, resistant; S, sensitive; I, intermediate.

sequence typing identified 2 clonal complexes: ST38 (3 strains) and ST10 (1 strain). The fifth strain could not be classified into any clonal complex (Table 2).

E. coli strains were classified into phylogenetic groups by multiplex PCR, described by Clermont et al. (12). The 3 strains in clonal complex ST38 belonged to the potentially virulent phylogenetic group $\mathrm{D}$; the other 2 belonged to group B2 (Table 2).

A PCR method was used to detect genes encoding for typical EAEC virulence factors (2). These genes include aggA and aafA (encoding for adhesions); aap (for dispersin); aatA (for TolC); aggR (for regulation of aggregation); astA, set $1 A$, and sen (for toxins), fyu $A$ (for iron recruitment); agn43 (for antigen 43); and genes encoding for serine protease autotransporter toxins such as pet and sat. Gene aatA was detected in the 5 strains, whereas aap, aggR, and aggA had positive amplification for only 2 of the strains belonging to ST38. The other genes detected are shown in Table 2. EAEC was also identified by typical adherence to HEp- 2 cells.

To determine the genetic environment of the $b l a_{\mathrm{CTX}-\mathrm{M}-15}$ gene, we designed an inverse PCR. We designed the primers by studying the gene sequence and were directed outside the gene. The ISEcp1 insertion sequence was upstream from the $b l a_{\mathrm{CTX}-\mathrm{M}-15}$ gene, which was also confirmed by PCR of the specific insertion sequence. To confirm the possible relationship between ISEcp1 and the resistance bla $a_{\text {СТХ-M-15 }}$ gene we conducted a PCR with the forward primer for the ISEcP1 and the reverse primer for the $b l a_{\mathrm{CTX}-\mathrm{M}-15}$ gene.

For plasmid extraction of the 5 isolates, we used the method of Kado and Liu (13). Only 3 strains had plasmids ranging from $93 \mathrm{~kb}$ to $170 \mathrm{~kb}$ (Figure 2, panel A). To confirm the absence of plasmids in the 2 strains, we conducted S1 digestion of the strains, resolving chromosomal DNA from plasmidic DNA. Southern blot of this digestion showed that the $b l a_{\text {CTX-M-15 }}$ gene was chromosomally located in these 2 strains, as was the aatA gene (usually found in the plasmid contained in EAEC strains) (data not shown). Finally, the location of the $b l a_{\text {СTX-M-15 }}$ gene in the 3 plasmid-containing strains was analyzed by using Southern blot from the plasmid extraction. The bla $a_{\text {СТХ-M-15 }}$ gene was located in a plasmid in the 3 strains. The size of the plasmid containing CTX-M-15 varied in each strain (Figure 2, panel B). Plasmids with specific known molecular weight were used to provide a range of the size of the plasmids studied.

\section{Conclusions}

We identified several features concerning the molecular epidemiology of CTX-M-15-producing EAEC isolates in India. First, all strains belonged to phylogenetic groups D and B2, the 2 groups most commonly found with E. coli infections (14). Second, not finding ST131 suggests that ST131 might not be the most common ST among EAEC strains from India and that clonal complex ST38 might play a large role in causing infectious intestinal diseases. Third, the $b l a_{\text {CTX-M-15 }}$ gene is not only located in the plasmid but may also be in the chromosome. However, previous reports have shown that $b l a_{\text {CTX-M-15 }}$ is consistently linked with ISEcp1, which means that the chromosomal location might have originated from a previous plasmid location that was part of either a transposon or a cassette within an integron (9). It is also worth noting that the size of the plasmids containing the $b l a_{\mathrm{CTX}-\mathrm{M}-15}$ gene was not the same in all strains, indicating that this gene may be located in different types of plasmids.

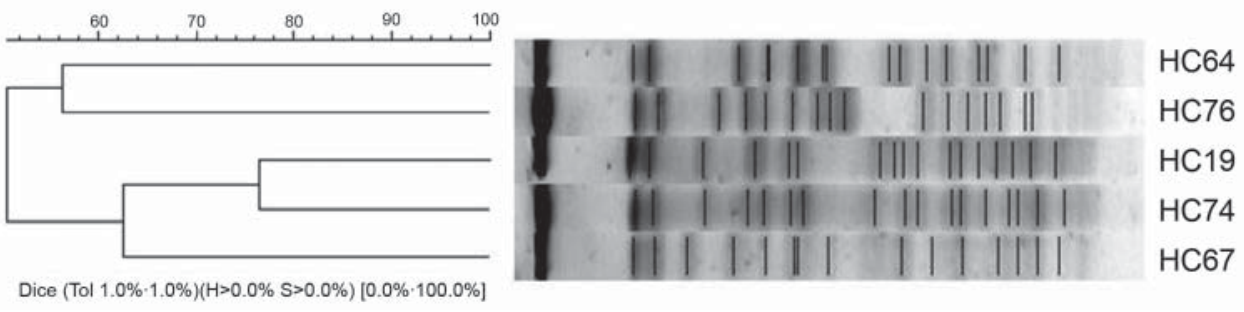

Figure 1. Cluster analysis of the enteroaggregative Escherichia coli strains from the pulsedfield gel electrophoresis fingerprinting. 
Table 2. Analysis results for 5 enteroaggregative Escherichia coli strains that produced travelers' diarrhea in patients returning from India, 2005-2006*

\begin{tabular}{lccccc}
\hline Strain & PFGE type & MLST clonal complex & Phylotype & $\begin{array}{c}\text { Genes encoding for } \\
\text { virulence factors }\end{array}$ & blactX-M-15 location \\
\hline HC19 & A & ST38 & D & aat, aap, aggR, aggA & Chromosome \\
HC64 & B & None & B2 & aat, astA, sat & Plasmid \\
HC67 & C & ST38 & aat, astA & Plasmid \\
HC74 & A & ST38 & D & aat, aap, aggR, aggA, & Chromosome \\
& & & afn43, fyuA & aat, fyuA & Plasmid \\
HC76 & D & ST10 & & & \\
\hline${ }^{*}$ PFGE, pulsed-field gel electrophoresis; MLST, multilocus sequence type; ST, sequence type. & &
\end{tabular}

This evidence of widespread distribution and flexibility of the $b l a_{\text {CTX-M-15 }}$ gene highlights the need to develop appropriate means to control dissemination of this gene and associated resistance genes. Epidemiologic surveillance and correct use of antimicrobial agents will help prevent the steady increase of antimicrobial drug resistance worldwide.

\section{Acknowledgments}

We thank R. Rodicio and I. Montero for their help with the plasmid extraction method.

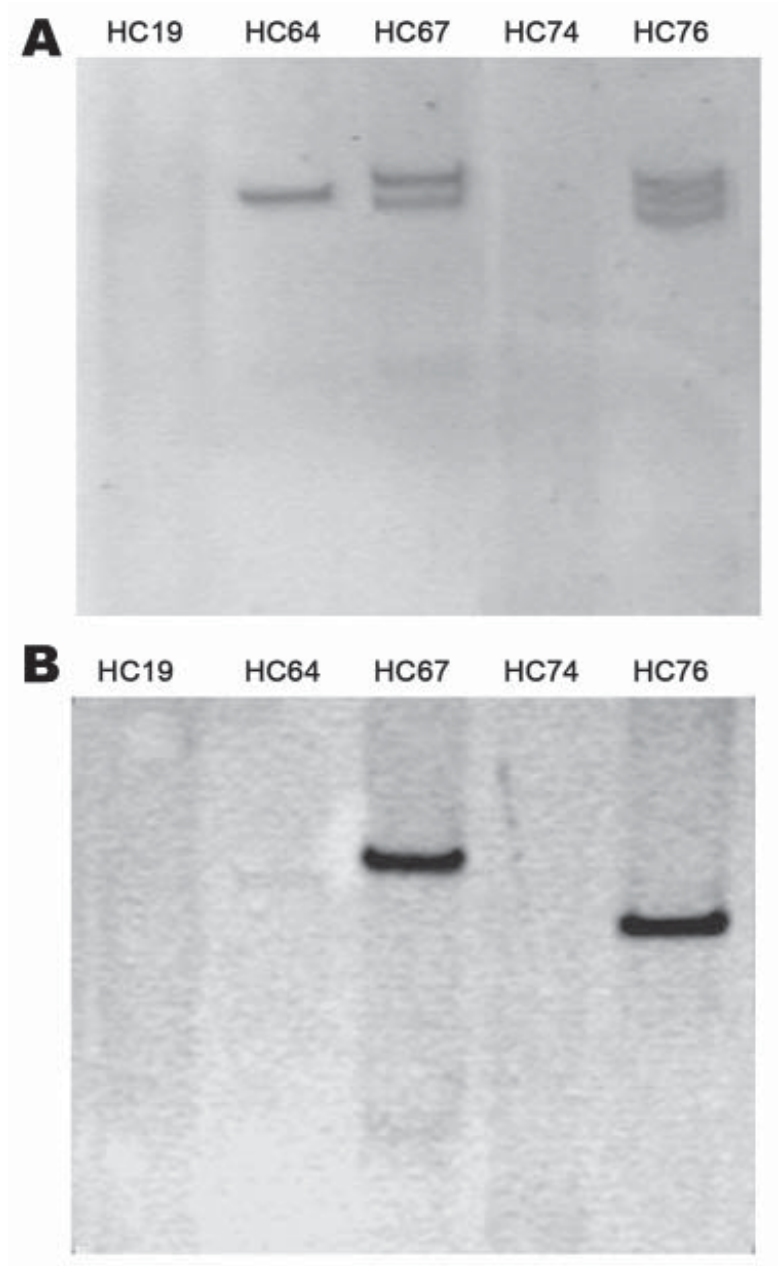

Figure 2. Plasmidic profile of the enteroaggregative Escherichia coli strains $(A)$ and Southern blotting of the bla CTX-M-15 $_{15}$ gene $(B)$.
S.M.S. received funding from contract "Miguel Servet" (CP05/00140) from "Fondo de Investigaciones Sanitarias" from the Spanish Ministry of Health. This study was supported by the Generalitat de Catalunya, Departament d'Universitats, Recerca i Societat de la Informació (2009 SGR 1256), by the Ministerio de Sanidad y Consumo, Instituto de Salud Carlos III, Spanish Network for the Research in Infectious Diseases (REIPI RE06/0008), by the European Community (TROCAR contract HEALTH-F3-2008-223031).

Ms Guiral is a PhD student with the Microbiologist Research Team at the August Pi i Sunyer Biomedical Research Institute in Barcelona. Her research interests include the genetic characterization of antimicrobial drug-resistant bacteria, especially all $E$. coli pathotypes.

\section{References}

1. Mendez Arancibia E, Pitart C, Ruiz J, Marco F, Gascón J, Vila J. Evolution of antimicrobial resistance in enteroaggregative Escherichia coli and enterotoxigenic Escherichia coli causing traveller's diarrhoea. J Antimicrob Chemother. 2009;64:343-7. doi:10.1093/ $\mathrm{jac} / \mathrm{dkp} 178$

2. Flores J, Okhuysen PC. Enteroaggregative Escherichia coli infection. Curr Opin Gastroenterol. 2009;25:8-11. doi:10.1097/ MOG.0b013e32831dac5e

3. Zahar JR, Bille E, Schnell D, Lanternier F, Mechai F, Masse V, et al. Extension of $\beta$-lactamases producing bacteria is a worldwide concern [in French]. Med Sci (Paris). 2009;25:939-44. doi:10.1051/ medsci/20092511939

4. Cantón R, Coque TM. The CTX-M $\beta$-lactamase pandemic. Curr Opin Microbiol. 2006;9:466-75. Epub 2006 Aug 30. doi:10.1016/j. mib.2006.08.011

5. Poirel L, Gniadkowski M, Nordmann P. Biochemical analysis of the ceftazidime-hydrolysing extended-spectrum beta-lactamase CTXM-15 and of its structurally related $\beta$-lactamase CTX-M-3. J Antimicrob Chemother. 2002;50:1031-4. doi:10.1093/jac/dkf240

6. Coque TM, Novais A, Carattoli A, Poirel L, Pitout J, Peixe L, et al. Dissemination of clonally related Escherichia coli strains expressing extended-spectrum $\beta$-lactamase CTX-M-15. Emerg Infect Dis. 2008;14:195-200. doi:10.3201/eid1402.070350

7. Oteo J, Diestra K, Juan C, Bautista V, Novais A, Pérez-Vázquez M, et al. Extended-spectrum $\beta$-lactamase-producing Escherichia coli in Spain belong to a large variety of multilocus sequence typing types, including ST10 complex/A, ST23 complex/A and ST131/B2. Int J Antimicrob Agents. 2009;34:173-6. doi:10.1016/j.ijantimicag. 2009.03.006 
8. Peirano G, Pitout JD. Molecular epidemiology of Escherichia coli producing CTX-M $\beta$-lactamases: the worldwide emergence of clone ST131 O25:H4. Int J Antimicrob Agents. 2010;35:316-21. doi:10.1016/j.ijantimicag.2009.11.003

9. Eckert C, Gautier V, Saladin-Allard M, Hidri N, Verdet C, OuldHocine Z, et al. Dissemination of CTX-M-type $\beta$-lactamases among clinical isolates of Enterobacteriaceae in Paris, France. Antimicrob Agents Chemother. 2004;48:1249-55. doi:10.1128/AAC.48.4.12491255.2004

10. Durmaz R, Otlu B, Koksal F, Hosoglu S, Ozturk R, Ersoy Y, et al. The optimization of a rapid pulsed-field gel electrophoresis protocol for the typing of Acinetobacter baumannii, Escherichia coli and Klebsiella spp. Jpn J Infect Dis. 2009;62:372-7.

11. Tartof SY, Solberg OD, Manges AR, Riley LW. Analysis of a uropathogenic Escherichia coli clonal group by multilocus sequence typing. J Clin Microbiol. 2005;43:5860-4. doi:10.1128/ JCM.43.12.5860-5864.2005
12. Clermont O, Bonacorsi S, Bingen E. Rapid and simple determination of the Escherichia coli phylogenetic group. Appl Environ Microbiol. 2000;66:4555-8. doi:10.1128/AEM.66.10.4555-4558.2000

13. Kado CI, Liu ST. Rapid procedure for detection and isolation of large and small plasmids. J Bacteriol. 1981;145:1365-73.

14. Saeed MA, Haque A, Ali A, Mohsin M, Bashir S, Tariq A, et al. Relationship of drug resistance to phylogenetic groups of $E$. coli isolates from wound infections. J Infect Dev Ctries. 2009. 22;3(9):66770 .

Address for correspondence: Jordi Vila, Department of Microbiology, Hospital Clínic, Villarroel 170, 08036 Barcelona, Spain; email: jvila@, ub.edu

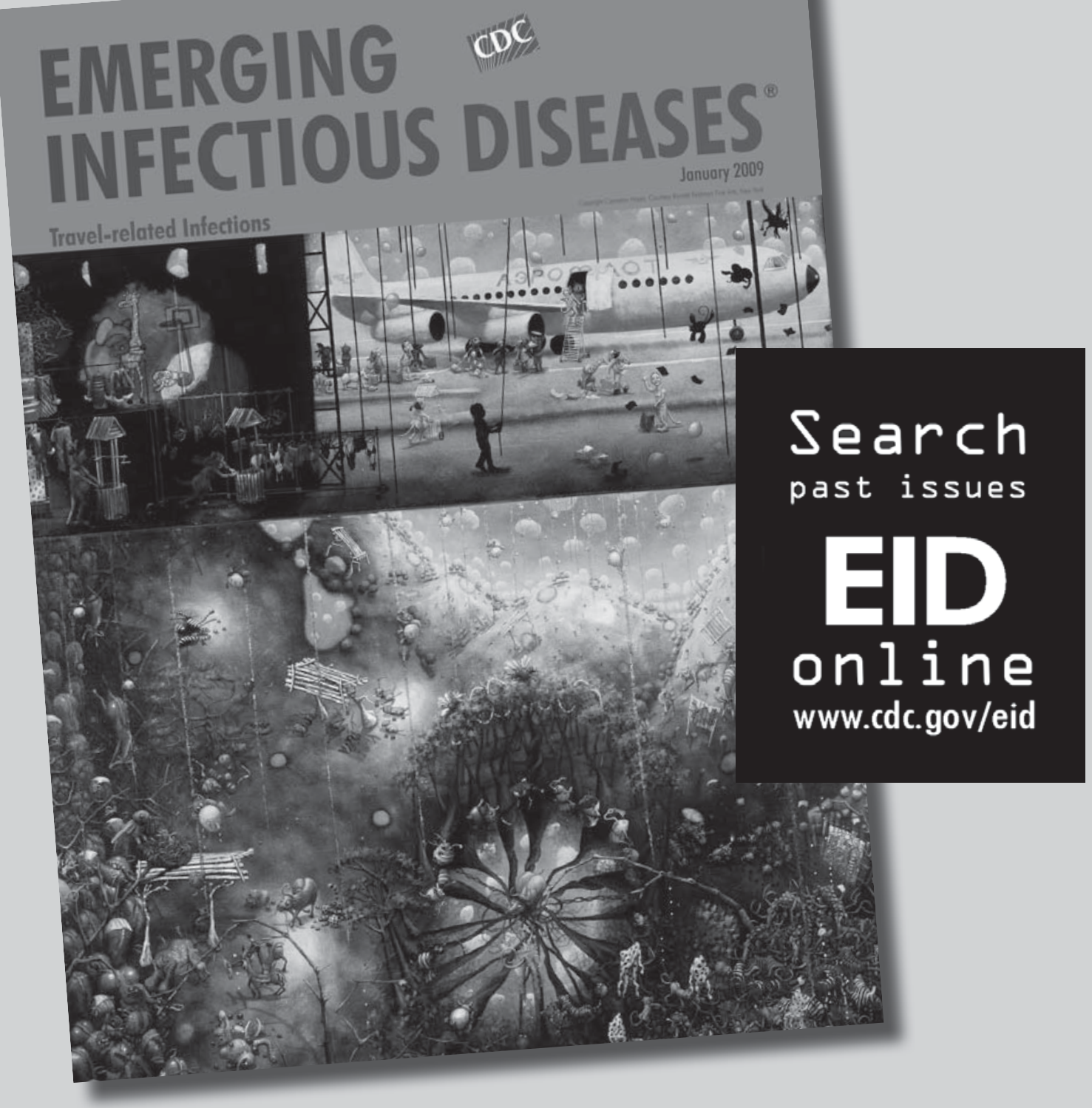

